\title{
Participative development of packages in the food industry - evaluation of ergonomics and productivity by objective measurements
}

\author{
Mikael Forsman ${ }^{\mathrm{ab}, \mathrm{b}}$, Eva Bernmark ${ }^{\mathrm{a}}$, Birgitta Nilsson ${ }^{\mathrm{c}}$, Sandra Pousette ${ }^{\mathrm{c}}$, Svend Erik Mathiassen ${ }^{\mathrm{b}}$ \\ ${ }^{a}$ Department of Public Health Sciences, Division of Occupational and Environmental Medicine, Karolinska Insti- \\ tutet, SE-171 76 Solna, Sweden. \\ ${ }^{\mathrm{b}}$ Department of Occupational and Public Health Sciences, Centre for Musculoskeletal Research, Faculty of \\ Health and Occupational Studies, University of Gävle, SE-801 76 Gävle, Sweden \\ ${ }^{c}$ Innventia AB, Box 5604, SE 11486 Stockholm, Sweden
}

\begin{abstract}
Rationalizations generally have a negative effect on health and known risk factors for musculoskeletal disorders. These effects may be reduced by paying attention to modifiers as worker participation and a resonant management style. In this study a participatory approach was used in the food industry in order to improve ergonomics and productivity. The food industry shows a high prevalence of musculoskeletal disorders, and repetitive manual work occurs extensively. Prototypes of new packaging solutions were developed in three cases, and compared in a simulated production to the existing production system through direct measurements of working postures and muscle activity, ratings of physical load, and general productivity data. Measured and rated ergonomic exposures showed that workload was significantly lower for the prototypes, in all three cases. In two cases, the number of handling operations included in the packaging operations were greatly reduced with the prototype package, as were production costs. The impact on disorders of the obtained load reductions is difficult to assess, but we believe that in "critical" situations like this, even small improvements may have an effect. This study shows that workloads during manual handling of packages as well as production costs can be reduced by applying participative development of packages.
\end{abstract}

Keywords: packages, productivity, inclinometry, goniometry, electromyography

\section{Introduction}

In a recent review, Westgaard and Winkel [1], evaluated 162 rationalization studies. They showed that rationalizations in general have a negative effect on health and suspected risk factors (57\% negative, $19 \%$ positive). The authors also concluded that most rationalizations do not have an occupational health focus, and that the negative health effects may be reduced by giving attention to modifiers such as worker participation, a resonant management style, information, support, group autonomy and procedural justice. Participatory ergonomics focus on worker participation and management support. Although participatory interventions have shown to be more successful than other ergonomic interventions [2,3], the approach does not necessarily lead to positive effects [4].

Extensive manual handling is a risk factor for work-related musculoskeletal disorders in the lower back and neck-shoulder regions. In the Swedish food industry, manual handling occurs mainly in production and in packing, and it is often carried out by women. Female workers in the food industry are also frequently suffering from work related musculoskeletal disorders; sixteen percent of the female operators in the Swedish food industry have responded that they during the last year have been absent from work because of work related disorders, accidents excluded, the average level is 8 percent [5]. The type and structure of packages is a likely determinant of working conditions and ergonomic exposures.

\footnotetext{
*Corresponding author. E-mail: mikael.forsman@ki.se
} 
The purpose of this study was to apply a participative approach for developing alternative packing solutions in food industry cases where packages were manually handled extensively and repetitively.

\section{Methods}

Three small to medium sized companies in the food industry, where packages were manually handled by female workers, participated.

\subsection{The three participating companies}

In total 24 female workers from the three companies actively participated and contributed with comments and suggestions for improvements of the packages and their own work situation.

Göteborgs Kex was founded in 1888 in Kungälv, western Sweden. The company has about $500 \mathrm{em}-$ ployees, mostly women. The company produces dry biscuits. Its products are sold through large Swedish retailers and go on export. The production division operates 3 shifts and for this case study, a section with 6 people working on each shift performing packaging tasks, participated, see Figure 1.

Jästbolaget opened in Rotebro, north of Stockholm, in 1893. It has now 60 employees, both men and women. Six females work in 2 shifts with manual handling of packages for dry yeast. The products are sold through wholesalers, retailers, directly to individual manufacturers and go on export.

Karamellpojkarna in Alingsås, western Sweden, was founded in 1952. The company has $30 \mathrm{em}-$ ployees, all working daytime. Eight women work with manual handling of packaging in a section packing confectionary that is sold through large Swedish retailers and go on export.

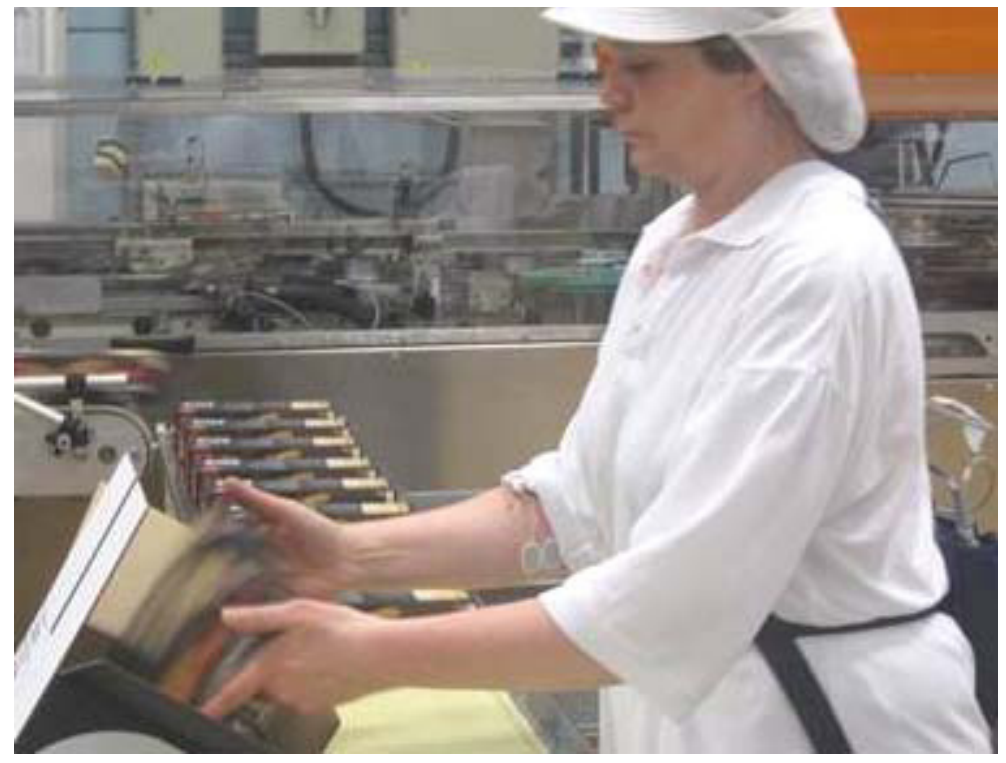

Figure 1. Manual handling of packages at Göteborgs Kex.

\subsection{Procedures}

The following steps were implemented at selected production lines at the food companies:

- Collection of production data and description of all manual activities devoted to manual handling of packages.
- Group discussions with workers concerning packaging characteristics supporting or obstructing easy handling; followed by suggestions for improvements.

- As a further participative approach, interviews were also carried out in the package value chain following after the food companies, i.e. "downstream" in the value chain, e.g. bakers and shop replenishers, 
searching suggestions for improvements to the selected packages.

- Discussions with packaging producers, i.e. "upwards" in the value chain, regarding improvements of the selected packages.

- Development of prototypes of new packages, and simulated production using the prototypes, during which productivity and ergonomics exposures were evaluated and compared to the "old" production system.

- Communication of the results to each company, and at a common open meeting.

\subsection{Evaluations of prototypes}

Direct measurements of working postures and muscle activity of the upper body were collected, together with ratings of physical load using questionnaires, and productivity data.

Postures and movement velocity of the upper back and upper arm were measured using inclinometers in all three companies. The muscular activity of the forearm flexor muscles was measured using electromyography (EMG), at Göteborgs Kex and Jästbolaget. Wrist postures and movements were recorded using goniometers at Jästbolaget. The measurements were carried out using procedures and equipment as described by Hansson [6] and Bernmark [7].

Productivity was estimated on the basis of company information, interviews, observations, video materials. An evaluation of production efficiency was made against the background of each particular company's accounting system, adhering to standard methods in loss analysis [8,9].

\section{Results}

The three companies showed a great commitment and a desire to come around problems associated with manual handling of packaging. They allocated time and staff resources, offered rooms for meetings, had in-house discussions with their purchasers and their marketing departments, and consulted external suppliers regarding existing packages.

Both measured and rated ergonomic exposures indicated that the workload was lower for the prototypes than for the original packages. None of the new prototype solutions had negative effects on productivity. At Jästbolaget and Karamellpojkarna, the number and the time of handling operations included in the packaging operations was greatly reduced with the prototype package.

\subsection{Göteborgs Kex}

The results from the focus groups showed that the Salinas biscuit package (Fig. 1) was the most difficult package to handle in the production, both in primary and secondary packaging. The focus group participants pointed out this package as the best candidate for change.

Interviews with the next segment in the value chain, i.e. employees at grocery retailers, showed that the packages were slippery, and that the secondary packaging was time consuming and difficult to handle since it broke up into too many pieces when being flattened.

The "slipperiness" of the primary packaging was the major target for change mentioned by the participants. The slipperiness was evident when grabbing bundles of the flat boxes when loading the packaging machine. It was difficult to grab four filled packages at a time and put them into corrugated board boxes.

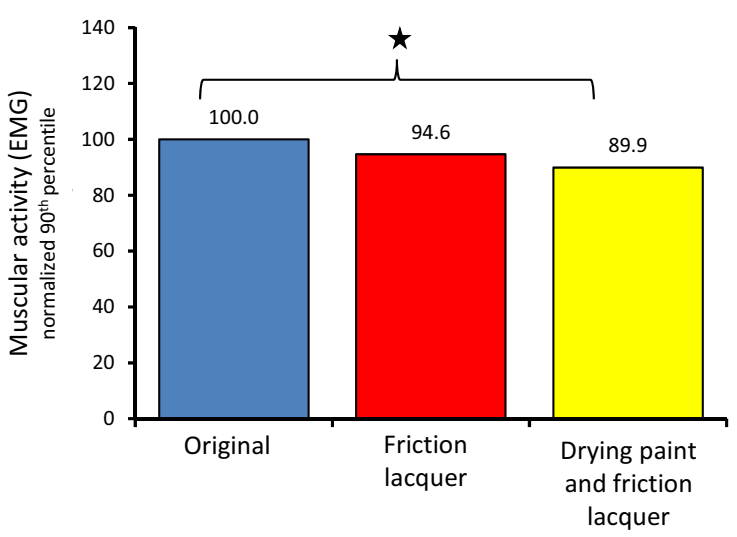

Fig. 2. Average load $(\mathrm{N}=9)$ for the forearm flexors in the right and left arms, 90 percentiles for the approx. 6 minute long test periods, standardized against the individual evaluations of the original "blue" boxes. The boxes with friction lacquer and quick drying ink (yellow) showed a significantly larger load (90 percentiles) than the original boxes $(\mathrm{p}=0.01)$, which are marked with asterisks in the figure.

The development phase resulted in two prototypes of Salinas boxes. One of the prototypes had only friction lacquer on it ("red"), while the other prototype had both fast-drying ink and a friction lacquer ("yellow"). In a blinded design, comparative subjective evaluations were made handling the original and the two prototypes. The measurements of postures and movements during packaging showed very small 
differences between the box types in back and arm movements. However, the mean $90^{\text {th }}$ percentile forearm flexor muscle activity was significantly $(\mathrm{p}<0.01)$ lower for the yellow box than for the original "blue" package (figure 2).

\subsection{Jästbolaget}

The focus group documentation phase showed that the production line transferring $500 \mathrm{~g}$ dry yeast primary packages into larger secondary packaging boxes was deemed the most interesting for being included in the project.

The results of the measurements of working postures and working movements (on 4 female workers) showed that the new prototype packaging led to a significant reduction in physical work load. Both muscular activity (reduced by $43.6 \%$ ) and postural load were significantly lower during work at the prototype test work station. Furthermore, the prototype was rated to be less strenuous.

In the changed production line, the number of work activities was reduced drastically from nine to three. According to the subjective assessments, the prototypes were easier to handle than the original packaging at those working stages left in production. In a productivity context, the new packaging and packaging equipment eliminated several working movements, thus generating new available working time.

\subsection{Karamellpojkarna}

The focus groups commented that several production lines had strenuous handling of packages. The company selected a secondary package of corrugated board as the candidate for change. It was manually raised and manually filled with candy bags.

In the development phase the producer of the secondary packaging of corrugated board suggested alternative easier-to-handle designs, also acknowledging considerations from the retail sector.

Eight women, all experienced at the production line participated in the evaluation of the prototype.

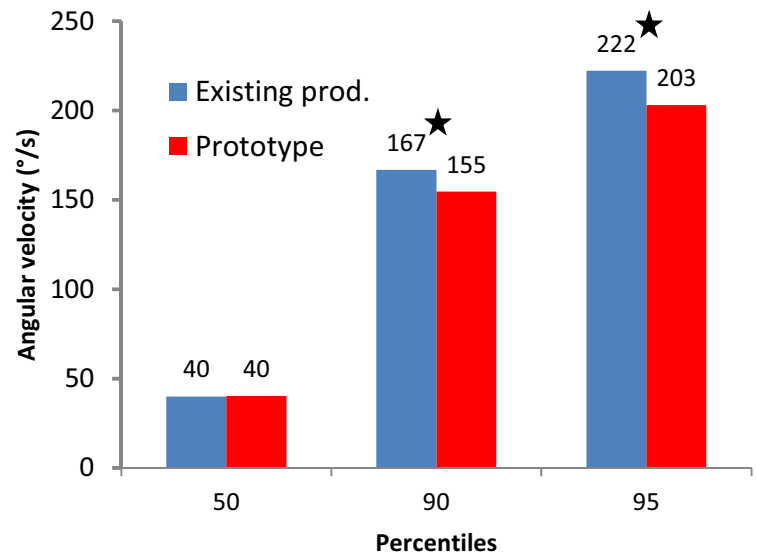

Fig. 3. Group mean values $(\mathrm{N}=8)$ of percentiles of angular velocity in the flexion/extension plane for right hand. Stars indicate significant differences $(\mathrm{p}<0.05)$.

The "peak" $90^{\text {th }}$ percentile of wrist velocity decreased significantly for both hands (by $7 \%, \mathrm{p}<0.05$, see Fig. 3), while the postural measurements showed no significant differences between the existing solution and the prototype. The ratings were more positive for the prototype, but it was commonly agreed that the prototype needed further development.

In this case, as with Jästbolaget, the numbers of handling operations included in the initial packaging operations were greatly reduced.

\section{Discussion}

In all three cases, significant differences in working postures and/or muscle activity could be documented among the existing production and the prototype solutions. In two out of three companies, the prototypes were judged by the workers to be considerably better than the existing solution. In the third company, a majority of the participants rated the prototypes to be better, while stating that it had disadvantages that needed further attention.

The investigated occupational group has, according to general statistics, a high prevalence of musculoskeletal disorders, and their work is often manual and repetitive. Even though it is difficult to assess the exact impact on disorders of reductions in ergonomics load of the size resulting from using our prototypes, we believe that in a "critical" situation like this, even small improvements may have an effect. We expect this effect to be most noticeable in the case of Karamellpojkarna, where peak wrist movement speeds were reduced considerably, from levels 
known to increase the risk for hand-arm disorders [10].

While our study was primarily devoted to parts of the packaging value chain where packages are handled, a comprehensive view on ergonomics in packaging need include also stakeholders involved in producing the packages. Thus, many parties can be engaged for a packed commodity. It was illustrated by the example at Götebors Kex, where approximately eight different suppliers of materials, ink, and lacquer etc. contributed to the packaging system for the biscuits. Also, from our experiences, we believe that the users "downstream" in the value chain possess very important experiences that can help in developing ergonomically better packages.

The present project focused on female handlers of packaging, since it was part of a larger initiative from a Swedish research funder concerning working conditions of women working in industry. When recruiting companies, we checked specifically whether women were involved in handling packages manually in the company. In the three studied companies, males worked only to a limited extent with handling of the investigated packages.

We conclude that workloads during manual handling of packages can be reduced by applying a participative development process for modifying the packages. This study showed that the participative approach may not only decrease load; it may also improve productivity.

\section{References}

[1] R.H. Westgaard, J. Winkel, Occupational musculoskeletal and mental health: Significance of rationalization and opportunities to create sustainable production systems - A systematic review, Appl Ergon. (2011), 42: 261-96.

[2] B. Silverstein, R. Clark, Interventions to reduce work-related musculoskeletal disorders, Journal of Electromyography and Kinesiology (2004), 14, 135-152.

[3] R.H. Westgaard, J. Winkel, Ergonomic intervention research for improved musculoskeletal health: a critical review. International Journal of Industrial Ergonomics 20, 463-500.

[4] D.C. Cole, N. Theberge, S.M. Dixon, I. Rivilis, W.P. Neumann and R. Wells, Reflecting on a program of participatory ergonomics interventions: a multiple case study, Work (2009), 34, 161-78

[5] Statistics Sweden. Work-Related Disorders 2010. www.av.se

[6] G.Å. Hansson, Methods for measuring physical workload with relevance for musculoskeletal disorders of neck and upper limb. Ph.D. Thesis, 2000, Lunds Universitet, Sweden.

[7] E. Bernmark, 2011, Measurements of physical workload with special reference to energy expenditure and work postures. Ph.D. Thesis, 2011, Karolinska Institutet, Sweden.

[8] S. Tangen, A Theoretical Foundation for Productivity Measurement and Improvement of Automatic Assembly Systems, Report TRITA-IIP-02-11, (2002), KTH, Stockholm, Sweden.

[9] S. Shingo, A study of the Toyota Production System: From an Industrial Engineering Viewpoint, Productivity Press Inc., 1989, Portland, Oregon, USA

[10]C. Nordander, K. Ohlsson, I. Åkesson, I. Balogh, G.-Å. Hansson, U. Strömberg, et al., Risk of musculoskeletal disorders among females and males in repetitive/constrained work. Ergonomics (2009), 52, 1226-1239 